\title{
Path Analysis and Diversity Studies for Growth, Earliness, Yield and Quality Parameters in Wild Melon (Cucumis melo subsp. agrestis) Genotypes
}

\author{
Shivappa M. Karadi", V.M. Ganiger, G. Bhuvaneshwari, \\ H.P. Hadimani, M.B. Madalageri and H.M. Pallavi \\ Department of Vegetable Science, College of Horticulture, University of Horticultural Sciences, \\ Bagalkot-587 103, Karnataka, India \\ *Corresponding author
}

\section{A B S T R A C T}

A field investigation was carried out with twenty four genotypes of wild melon to study the path analysis and diversity studies for different quantitative and qualitative characters.

Keywords Path analysis studies revealed that significant positive association at genotypic level among the traits viz., leaf area (0.824), number of fruits per vine (1.364), fruit length

Path analysis, (0.474), fruit diameter (1.259), cavity size (0.236), fruit flesh thickness $(0.769)$, Total

Diversity and

Cluster analysis in wild melon genotypes. soluble solids $(0.204)$ and vitamin $\mathrm{C}(0.152)$ had exhibited true association with direct effect on yield per plant. The direct selection for these traits would be rewarding for improvement in the total yield per plant. Genetic diversity was studied with same genotypes. The genotypes were grouped into eight clusters with irrespective of geographic

\section{Article Info}

Accepted:

12 October 2017

Available Online:

10 December 2017 divergence, indicating no parallelism between geographic and genetic diversity. The maximum number of genotypes (17) was found in cluster 1 with intra-cluster distance of (22.12). The maximum inter-cluster distance was observed between cluster III and cluster VIII (97.23). Hence, genotypes belonging to these clusters may be utilized for involving in hybridization program for crop improvement. The among 18 characters included for $\mathrm{D}^{2}$ analysis, vitamin $\mathrm{C}$ content $(71.01 \%)$ followed by fruit flesh thickness $(20.65 \%)$, fruit cavity size $(3.99 \%)$ and leaf area $(1.88 \%)$ contributed more for genetic divergence.

\section{Introduction}

Wild melon has more regional preferences for specificity of fruits trait yellow color with white stripped. Considering the potentiality of this crop, there is a prime need for improvement and to develop varieties suited to specific agro-ecological conditions and also for specific use.

The path coefficient technique helps in estimating direct and indirect contribution of various components in building up the total correlation towards yield. On the basis of these studies, the quantum importance of individual character will facilitate the selection programme for better gains. Path analysis also measures the relative importance of causal factors involved. This is simply a standardized partial regression analysis, where in total correlation values were subdivided into causal factors (Shipley, 2000). Keeping this in view, the present investigation was aimed at assessing the diversity of various characters and direct and indirect path effects of eighteen independent 
components on fruit yield in twenty four genotypes. Information on genetic diversity among available germplasm is vital to a plant breeder for an efficient choice of parents for hybridization. It is established fact that genetically diverse parents are likely to contribute desirable segregants. Some of the experts like Harington (1940) and Arunachalam (1981) were also observed that the more diverse parents, greater are the chance of obtaining high heterotic $F_{1} s$ and broad spectrum of variability in segregating generation. Improvement on yield and quality can be achieved by selecting genotypes with desirable character combinations existing in the nature or by hybridization. Election of parents identified on the basis of divergence analysis would be more promising for a hybridization programme. Such parents are expected to produce superior segregants in combination with others and thus are most valuable for breeder.

The present investigation was conducted by keeping major objective as to study the path analysis and diversity studies for growth, earliness, yield and quality parameters in wild melon (Cucumis melo subsp. agrestis) genotypes.

\section{Materials and Methods}

The experiment was conducted at the Research Block of Vegetable Section in haveli farm under the University of Horticultural Sciences, Bagalkot (Karnataka) during the year 2013-14. Twenty four genotypes of wild melon were grown in randomized completely block design with two replications. Randomly chosen plant in each replication of each entry were labeled and used for observations for the growth parameters viz., vine length $(\mathrm{cm})$, leaf area $\left(\mathrm{cm}^{2}\right)$, number primary branches per vine, at 45, 60 and 90 days after sowing. Earliness parameters viz., days to first male flowering, days to first female flowering, node at first male flowering and node at first female flowering and yield parameters viz., number of fruits per vine, average fruit weight $(\mathrm{g})$ fruit length $(\mathrm{cm})$, fruit diameter $(\mathrm{cm})$ and yield per vine $(\mathrm{kg})$ and quality parameters viz., fruit cavity size $\left(\mathrm{cm}^{2}\right)$, number of seeds per fruit, fruit flesh thickness (cm),TSS ( ${ }^{0}$ brix) by Erma hand refractometer vitamin C (mg/100g) by Sadasivam and Manikam, 1991 and seed to pulp ratio. Genotypic and phenotypic of direct and indirect effects were computed by using procedure given by Deway and Lu (1957). Genetic diversity was studied following with help of Mahalanobis (1936) generalized distance $\mathrm{D}^{2}$ extended by Rao (1952). Based on the $\mathrm{D}^{2}$ values, the genotypes were grouped into clusters following the method suggested Tocher's. Intra and inter cluster distance were calculated by the methods of Singh and Choudhary, 1985. Statistical analysis was carried out using WINDOSTAT software.

\section{Results and Discussion}

\section{Path analysis studies}

Though correlation analysis indicates the association pattern of component traits with yield, it simply represents the overall association of a particular trait with yield rather than providing cause and effect relationship. The technique of path coefficient analysis developed by Wright (1921) and demonstrated by Dewey and Lu (1957) facilitates in splitting the correlation coefficients into the measures of direct and indirect effects. It is a standardised by partial regression coefficient analysis. As such, it measures the direct influence of one variable upon other. Such information would be of great value in enabling the breeder to specifically identify important component traits of yield and utilize the genetic stock for improvement in a planned way. 
Table.1 Genotypic path coefficient analysis among growth, earliness, yield and quality parameters in wild melon (Cucumis melo subsp. agrestis)

\begin{tabular}{|c|c|c|c|c|c|c|c|c|c|c|c|c|c|c|c|c|c|c|}
\hline @ & 1 & 2 & 3 & 4 & 5 & 6 & 7 & 8 & 9 & 10 & 11 & 12 & 13 & 14 & 15 & 16 & 17 & rG \\
\hline 1 & -0.235 & -0.090 & -0.077 & -0.182 & -0.143 & 0.086 & 0.485 & 0.075 & -0.165 & 0.176 & 0.191 & 0.035 & -0.129 & 0.075 & 0.057 & -0.02 & -0.023 & 0.116 \\
\hline 2 & 0.025 & 0.824 & 0.085 & -0.199 & 0.002 & 0.009 & -0.02 & -0.595 & -0.647 & 0.229 & 0.594 & 0.134 & -0.133 & 0.349 & 0.041 & 0.021 & -0.080 & $0.639 * *$ \\
\hline 3 & -0.033 & -0.129 & -0.543 & 0.186 & -0.333 & 0.220 & 0.343 & -0.018 & 0.168 & -0.105 & 0.017 & -0.072 & -0.107 & 0.063 & 0.105 & 0.005 & 0.023 & -0.210 \\
\hline 4 & 0.069 & -0.264 & -0.163 & 0.623 & 0.074 & -0.071 & -0.214 & 0.382 & 0.471 & -0.217 & -0.563 & -0.143 & 0.084 & -0.318 & -0.089 & -0.053 & 0.066 & $-0.326^{*}$ \\
\hline 5 & -0.092 & -0.005 & -0.498 & -0.128 & -0.363 & 0.113 & 0.797 & -0.307 & -0.405 & 0.118 & 0.661 & 0.060 & -0.193 & 0.414 & 0.131 & 0.051 & -0.036 & $0.318 *$ \\
\hline 6 & -0.055 & 0.020 & -0.325 & -0.120 & -0.112 & 0.368 & -0.255 & -0.048 & -0.159 & 0.099 & 0.256 & 0.057 & -0.076 & 0.216 & 0.078 & 0.021 & -0.025 & -0.060 \\
\hline 7 & 0.090 & 0.013 & 0.148 & 0.106 & 0.229 & 0.074 & -1.259 & 0.578 & 0.459 & -0.129 & -0.534 & -0.062 & 0.108 & -0.164 & -0.111 & -0.004 & 0.046 & $-0.412 * *$ \\
\hline 8 & -0.013 & -0.36 & 0.007 & 0.174 & 0.081 & -0.013 & -0.533 & 1.364 & 0.867 & -0.260 & -1.090 & -0.161 & 0.255 & -0.552 & -0.167 & -0.063 & 0.097 & $-0.367 *$ \\
\hline 9 & -0.035 & 0.479 & 0.082 & -0.263 & -0.132 & 0.052 & 0.519 & -1.063 & -1.113 & 0.418 & 1.172 & 0.230 & -0.289 & 0.686 & 0.139 & 0.049 & -0.134 & $0.797 * *$ \\
\hline 10 & -0.087 & 0.399 & 0.120 & -0.286 & -0.090 & 0.077 & 0.344 & -0.749 & -0.981 & 0.474 & 0.938 & 0.205 & -0.289 & 0.571 & 0.117 & 0.010 & -0.120 & $0.653 * *$ \\
\hline 11 & -0.035 & 0.389 & -0.007 & -0.281 & -0.190 & 0.075 & 0.534 & -1.18 & -1.036 & 0.353 & 1.259 & 0.208 & -0.304 & 0.743 & 0.186 & 0.076 & -0.12 & $0.670 * *$ \\
\hline 12 & -0.034 & 0.469 & 0.166 & -0.377 & -0.093 & 0.090 & 0.333 & -0.934 & -1.086 & 0.412 & 1.111 & 0.236 & -0.268 & 0.653 & 0.123 & 0.058 & -0.133 & $0.726^{* *}$ \\
\hline 13 & -0.082 & 0.296 & -0.157 & -0.142 & -0.189 & 0.075 & 0.370 & -0.941 & -0.868 & 0.370 & 1.036 & 0.171 & -0.370 & 0.642 & 0.163 & 0.064 & -0.106 & $0.332 *$ \\
\hline 14 & -0.023 & 0.374 & -0.044 & -0.258 & -0.195 & 0.103 & 0.270 & -0.979 & -0.993 & 0.352 & 1.216 & 0.201 & -0.309 & 0.769 & 0.165 & 0.067 & -0.118 & $0.598 * *$ \\
\hline 15 & -0.066 & 0.165 & -0.279 & -0.272 & -0.234 & 0.140 & 0.687 & -1.11 & -0.758 & 0.273 & 1.149 & 0.143 & -0.296 & 0.622 & 0.204 & 0.037 & -0.08 & $0.325^{*}$ \\
\hline 16 & 0.031 & 0.177 & -0.018 & -0.216 & -0.122 & 0.052 & 0.036 & -0.569 & -0.364 & 0.032 & 0.627 & 0.090 & -0.157 & 0.339 & 0.050 & 0.152 & -0.053 & 0.087 \\
\hline 17 & -0.040 & 0.478 & 0.090 & -0.299 & -0.095 & 0.069 & 0.420 & -0.964 & -1.083 & 0.412 & 1.096 & 0.228 & -0.286 & 0.662 & 0.119 & 0.059 & -0.138 & $0.728 * *$ \\
\hline
\end{tabular}

Residual $(\mathrm{R})=1.029, @=$ Character, Bold and diagonal values indicate direct effect, $\mathrm{rG}=$ Genotypic correlation coefficient with fruit yield per vine, $*$ and $* *$ indicate significant at 5 and 1 per cent probability level, respectively

1. Vine length $(\mathrm{cm})$

2. Leaf area $\left(\mathrm{cm}^{2}\right)$

3. Number of primary branches

4. Days to first male flower

5. Days to first female flowering

6 . Node to first male flowering
7. Node to first female flowering

8. Number of fruits per vine

9. Average fruit weight $(\mathrm{g})$

10. Fruit length $(\mathrm{cm})$

11. Fruit breadth $(\mathrm{cm})$

12. Cavity size $\left(\mathrm{cm}^{2}\right)$
13. Number of seed per fruit

14. Fruit flesh thickness $(\mathrm{cm})$

15. TSS $\left({ }^{0}\right.$ brix $)$

16. Vitamin C (mg/ 100g)

17. Seed to pulp ratio

$\mathrm{rG}=$ Genotypic correlation with fruit yield 
Table.2 Phenotypic path coefficient analysis among growth, earliness, quality and yield parameters in wild melon (Cucumis melo subsp. agrestis)

\begin{tabular}{|c|c|c|c|c|c|c|c|c|c|c|c|c|c|c|c|c|c|c|}
\hline @ & 1 & 2 & 3 & 4 & 5 & 6 & 7 & 8 & 9 & 10 & 11 & 12 & 13 & 14 & 15 & 16 & 17 & $\mathbf{r P}$ \\
\hline 1 & -0.027 & -0.031 & 0.003 & 0.049 & -0.045 & -0.019 & 0.025 & 0.052 & 0.316 & -0.094 & 0.060 & -0.095 & -0.035 & -0.020 & 0.016 & 0.007 & -0.060 & 0.102 \\
\hline 2 & 0.003 & 0.288 & -0.009 & 0.059 & 0.000 & -0.003 & -0.001 & -0.380 & 1.262 & -0.127 & 0.260 & -0.386 & -0.036 & -0.103 & 0.012 & -0.010 & -0.209 & $0.621 * *$ \\
\hline 3 & -0.001 & -0.043 & 0.061 & -0.047 & -0.087 & -0.035 & 0.018 & 0.007 & -0.315 & 0.049 & 0.022 & 0.163 & -0.012 & -0.024 & 0.018 & 0.007 & 0.050 & -0.169 \\
\hline 4 & 0.006 & -0.082 & 0.013 & -0.209 & 0.029 & 0.020 & -0.009 & 0.237 & -0.855 & 0.107 & -0.234 & 0.377 & 0.022 & 0.089 & -0.021 & 0.025 & 0.159 & $-0.326^{*}$ \\
\hline 5 & -0.007 & 0.000 & 0.033 & 0.039 & -0.159 & -0.022 & 0.033 & -0.190 & 0.651 & -0.050 & 0.253 & -0.148 & -0.044 & -0.097 & 0.039 & -0.022 & -0.077 & 0.232 \\
\hline 6 & -0.005 & 0.010 & 0.023 & 0.046 & -0.039 & -0.091 & -0.011 & -0.032 & 0.308 & -0.051 & 0.112 & -0.162 & -0.020 & -0.062 & 0.020 & -0.008 & -0.067 & -0.029 \\
\hline 7 & 0.009 & 0.005 & -0.015 & -0.025 & 0.073 & -0.014 & -0.073 & 0.338 & -0.814 & 0.061 & -0.229 & 0.165 & 0.020 & 0.052 & -0.028 & 0.008 & 0.112 & $-0.355^{*}$ \\
\hline 8 & -0.001 & -0.121 & 0.005 & -0.054 & 0.033 & 0.003 & -0.027 & 0.908 & -1.678 & 0.141 & -0.469 & 0.454 & 0.068 & 0.162 & -0.048 & 0.034 & 0.253 & $-0.337 *$ \\
\hline 9 & -0.003 & 0.163 & -0.008 & 0.080 & -0.046 & -0.012 & 0.026 & -0.682 & 2.231 & -0.226 & 0.515 & -0.651 & -0.077 & -0.203 & 0.038 & -0.026 & -0.355 & $0.764 * *$ \\
\hline 10 & -0.003 & 0.139 & -0.011 & 0.085 & -0.003 & -0.017 & 0.017 & -0.488 & 1.915 & -0.26 & 0.411 & -0.586 & -0.078 & -0.171 & 0.033 & -0.006 & -0.313 & $0.637 * *$ \\
\hline 11 & -0.002 & 0.133 & 0.002 & 0.086 & -0.086 & -0.018 & 0.029 & -0.746 & 2.012 & -0.189 & 0.571 & -0.586 & -0.077 & -0.221 & 0.052 & -0.036 & -0.312 & $0.612 * *$ \\
\hline 12 & -0.003 & 0.163 & -0.014 & 0.115 & -0.034 & -0.021 & 0.017 & -0.603 & 2.128 & -0.226 & 0.491 & -0.682 & -0.072 & -0.198 & 0.035 & -0.029 & -0.350 & $0.717 * *$ \\
\hline 13 & -0.008 & 0.094 & 0.006 & 0.043 & -0.064 & -0.017 & 0.013 & -0.563 & 1.569 & -0.188 & 0.401 & -0.45 & -0.110 & -0.17 & 0.043 & -0.031 & -0.258 & $0.310 *$ \\
\hline 14 & -0.002 & 0.124 & 0.006 & 0.078 & -0.065 & -0.023 & 0.016 & -0.616 & 1.896 & -0.188 & 0.528 & -0.565 & -0.078 & -0.239 & 0.044 & -0.033 & -0.306 & $0.577 * *$ \\
\hline 15 & -0.007 & 0.057 & 0.017 & 0.068 & -0.096 & -0.028 & 0.032 & -0.674 & 1.320 & -0.134 & 0.456 & -0.374 & -0.073 & -0.164 & 0.065 & -0.020 & -0.190 & 0.255 \\
\hline 16 & 0.002 & 0.035 & -0.005 & 0.062 & -0.042 & -0.009 & 0.000 & -0.367 & 0.693 & -0.019 & 0.246 & -0.241 & -0.041 & -0.096 & 0.015 & -0.083 & -0.132 & 0.018 \\
\hline 17 & -0.004 & 0.163 & -0.008 & 0.090 & -0.033 & -0.016 & 0.022 & -0.623 & 2.150 & -0.223 & 0.483 & -0.648 & -0.077 & -0.199 & 0.033 & -0.030 & -0.369 & $0.711 * *$ \\
\hline
\end{tabular}

Residual $(\mathrm{R})=0.315, @=$ Character, Bold and diagonal values indicate direct effect, $\mathrm{rP}=$ Phenotypic correlation coefficient with fruit yield per vine, * and ** indicate significant at 5 and 1 per cent probability level, respectively

1. Vine length $(\mathrm{cm})$

2. Leaf area $\left(\mathrm{cm}^{2}\right)$

3. Number of primary branches

4. Days to first male flower

5. Days to first female flowering

6 . Node to first male flowering
7. Node to first female flowering

8. Number of fruits per vine

9. Average fruit weight $(\mathrm{g})$

10. Fruit length $(\mathrm{cm})$

11. Fruit breadth $(\mathrm{cm})$

12. Cavity size $\left(\mathrm{cm}^{2}\right)$
13. Number of seed per fruit

14. Fruit flesh thickness $(\mathrm{cm})$

15. TSS ( ${ }^{0}$ brix $)$

16. Vitamin C (mg/ 100g)

17. Seed to pulp ratio

$\mathrm{rG}=$ Genotypic correlation with fruit yield 
Table.3 Classification of wild melon genotypes into different clusters based on $\mathrm{D}^{2}$ value

\begin{tabular}{|c|c|l|}
\hline $\begin{array}{c}\text { Cluster } \\
\text { number }\end{array}$ & $\begin{array}{c}\text { Number of } \\
\text { genotypes }\end{array}$ & \multicolumn{1}{c|}{ Genotypes included } \\
\hline & & HUB-17, HUB-18, HUB-15, HUB-19, HUB-10, HUB-16, HUB-3, HUB- \\
I & 17 & $\begin{array}{l}\text { 2, HUB-7, HUB-1, HUB-4, HUB-24, HUB-14, HUB-9, HUB-8, HUB-5, } \\
\text { HUB-23. }\end{array}$ \\
II & 1 & HUB-20 \\
III & 1 & HUB-22 \\
IV & 1 & HUB-6 \\
V & 1 & HUB-13 \\
VI & 1 & HUB-11 \\
VII & 1 & HUB-21 \\
VIII & 1 & HUB-12 \\
\hline
\end{tabular}

Table.4 Average intra and inter-cluster $\mathrm{D}^{2}$ values of 8 clusters for 18 characters formed by 24 genotypes of wild melon (Cucumis melo subsp. agrestis) genotypes

\begin{tabular}{|c|c|c|c|c|c|c|c|c|}
\hline Clusters & I & II & III & IV & V & VI & VII & VIII \\
\hline I & $\mathbf{2 2 . 1 2}$ & 33.36 & 35.92 & 38.80 & 35.28 & 37.28 & 45.84 & 68.13 \\
\hline II & & $\mathbf{0 . 0 0}$ & 13.19 & 64.63 & 58.10 & 19.48 & 68.89 & 95.00 \\
\hline III & & & $\mathbf{0 . 0 0}$ & 67.78 & 60.58 & 21.38 & 73.29 & 97.23 \\
\hline IV & & & & $\mathbf{0 . 0 0}$ & 21.46 & 67.45 & 22.49 & 33.67 \\
\hline V & & & & & $\mathbf{0 . 0 0}$ & 57.59 & 21.18 & 41.20 \\
\hline VI & & & & & & $\mathbf{0 . 0 0}$ & 68.20 & 95.56 \\
\hline VII & & & & & & & $\mathbf{0 . 0 0}$ & 32.74 \\
\hline VIII & & & & & & & & $\mathbf{0 . 0 0}$ \\
\hline
\end{tabular}

Bold Diagonal indicates the intra cluster distance

Table.5 Relative per cent contribution of different characters to the total divergence in wild melon (Cucumis melo subsp. agrestis) genotypes

\begin{tabular}{|c|l|c|c|}
\hline Sr. no. & \multicolumn{1}{|c|}{ Character } & No. of times ranked first & Per cent contribution \\
\hline $\mathbf{1 .}$ & Vine length(cm) & 0 & 0.00 \\
$\mathbf{2 .}$ & Leaf area $\left(\mathrm{cm}^{2}\right)$ & 5 & 1.81 \\
$\mathbf{3 .}$ & Number of primary branches per vine & 0 & 0.00 \\
$\mathbf{4 .}$ & Days to first male flowering & 0 & 0.00 \\
$\mathbf{5 .}$ & Days to first female flowering & 0 & 0.00 \\
$\mathbf{6 .}$ & Node of first male flowering & 5 & 1.81 \\
$\mathbf{7 .}$ & Node of first female flowering & 0 & 0.00 \\
$\mathbf{8 .}$ & Number of fruits per vine & 1 & 0.36 \\
$\mathbf{9 .}$ & Average fruit weight $(\mathrm{g})$ & 0 & 0.00 \\
$\mathbf{1 0 .}$ & Fruit length $(\mathrm{cm})$ & 0 & 0.00 \\
$\mathbf{1 1 .}$ & Fruit breadth $(\mathrm{cm})$ & 1 & 0.36 \\
$\mathbf{1 2 .}$ & Yield & 0 & 0.00 \\
$\mathbf{1 3}$ & Fruit cavity size(cm $\left.{ }^{2}\right)$ & 11 & 3.99 \\
$\mathbf{1 4 .}$ & Number of seeds per fruit & 0 & 0.00 \\
$\mathbf{1 5 .}$ & Fruit flesh thickness $(\mathrm{cm})$ & 57 & 20.65 \\
$\mathbf{1 6 .}$ & TSS ( ${ }^{0}$ brix) & 0 & 0.00 \\
$\mathbf{1 7 .}$ & Vitamin C & 196 & 71.01 \\
$\mathbf{1 8 .}$ & Sees to pulp ratio & 0 & 0.00 \\
\hline
\end{tabular}


There are 17 important growth, earliness, yield and quality parameters subjected to genotypic and phenotypic path coefficient analysis by considering fruit yield per plant as dependent variable on 17 other independent variables are presented in Tables 1 and 2, respectively discussed only at genotypic level.

Among the 18 traits chosen for path analysis at genotypic level viz., leaf area (0.824) (Yadav and Ram, 2002), number of fruits per vine (1.364), fruit length (0.474), fruit diameter (1.259) (Vishwanth, 2003; Dora et al., 2002, Yadav and Ram, 2002; Kumaran et al., 2000), cavity size (0.236), fruit flesh thickness (0.769), total soluble solids (0.204) and vitamin C (0.152) (Rahman et al., 2002; Dhatt and Singh, 2008; Lal and Singh, 1997) had positive direct effect indicating their true positive and significant association with yield per plant.

\section{Diversity analysis studies}

\section{Cluster pattern}

The classification of wild melon genotypes into different clusters based on $\mathrm{D}^{2}$ value is given in Table 3. The material for present study includes 24 genotypes grouped into eight clusters using Tocher's method. Of the eight clusters, studied the cluster 1 was the largest having 17genotypes followed by remaining cluster II (HUB-20), cluster III (HUB-22), cluster IV (HUB-6), cluster V (HUB-13), cluster VI (HUB-11), cluster VII (HUB-21) and cluster VIII (HUB12) had one genotype. It is confirmed with the statement of Jack et al., (2004), Kale et al., (2002) and Kumar et al., (2013). Genotypes usually did not cluster according to geographical distributions. There is no any direct relationship between geographical distribution and genetic distance.

\section{Intra and inter cluster distance}

The average $\mathrm{D}^{2}$ values of intra and inter cluster distance are given in Table 4. Intra-cluster distances revealed that cluster I with 17 genotypes showed maximum intra-cluster diversity $\left(\mathrm{D}^{2}=22.12\right)$. The clusters II, III, IV, V, VI, VII and VIII had no intra-cluster distance $\left(\mathrm{D}^{2}=0.00\right)$ as they possessed single genotype. Maximum intra-cluster distance was observed in cluster I indicating existence of wide genetic divergence among the constituent genotypes in it as compared to other cluster. High degree of divergence among the genotypes within a cluster would produce more segregating breeding material and selection within such cluster might be executed based on maximum mean value for the desirable characters. Maximum inter-cluster $\mathrm{D}^{2}$ values was observed between the clusters III and VIII $\left(D^{2}=97.23\right)$ indicating that the genotypes in these clusters can be used as a parents in hybridization program to get higher heterotic hybrid and segregating population contribution of characters. The between cluster II and III had the least inter-cluster distance $\left(D^{2}=13.19\right)$ indicating that close relationship and less divergence between the genotypes included in these clusters.

\section{Per cent contribution of characters of genetic diversity}

Relative per cent contribution of different characters to divergence is given in Table 5 . Among these characters the vitamin $\mathrm{C}$ content $(71.01 \%)$ contributed maximum to the genetic diversity followed by fruit flesh thickness $(20.65 \%)$, fruit cavity size $(3.99 \%)$, leaf area $(1.88 \%)$, node at first male flowering $(1.81 \%)$, number of fruits per vine (0.36) and fruit breadth (0.36). Character like vine length, number of primary branches per vine, days to first male flowering, days to first female flowering, node at first female flowering, average fruit weight, fruit length, yield per vine, number of seed per fruit, TSS and seed to pulp ratio did not contribute to genetic divergence. It is confirmed with the statement of Pandey et al., 2013 and Lakshmi et al., 2003

\section{References}

Arunchalam, V., 1981. Genetic distances in plant breeding. Ind. J. Genet., 41: 226-236. 
Dewey, D. R. and Lu, K. H., 1957. A correlation and path coefficient analysis of components of wheat grass seed production. Agron. J., 51:515-518

Dhatt, A. S. and Singh, H., 2008. Genetic variability, correlation and path analysis in pumpkin. Crop Improvement. 35 (1) 91-94.

Dora, D. K., Behara, T. K., Acharya, G. C., Mohapatra, P. and Mishra. B., 2002, Genetic variability and characters association in pointed gourd (Trichosanthus dioica Foxb. W). Indian J. Hort., 60 (2) 163-166.

Harrington, J.B., 1940, Yielding capacity of wheat crosses as indicated by bulk hybrid tests. Canadian Journal of Research, 18: 578-584.

Jack, E., Staub, A. I. L., Opez, S. E. and Nikolaos, F., 2004. Diversity among melon landraces (Cucumis melo L.) from Greece and their genetic relationships with other melon germplasm of diverse origins. Euphytica, 136: 151-166.

Kale, V.S., Patil, B.R., Bindu, S. and Paithankar, D.H., 2002. Genetic divergence in pumpkin (Cucurbita moschata). J. Soil Crops, 12: 213-216.

Kumar, S., Kumar, D., Kumar, R., Thakur, K.S. and Dogra, B.S., 2013. Estimation of genetic variability and divergence for fruit yield and quality traits in cucumber (Cucumis sativus. L.) in North- western Himilays. Univ. J. Plant Sci., 1: 27-36.

Kumaran, S. S., Natarajan, S. and Thamburaj, S., 2000b. Correlation and path analysis studies in pumpkin Cucurbita moschata Duch. Ex. Poir.). South Indian Hort., 46 (3\&4):138-142.

Lakshmi, L.M., Haribabu, K. and Reddy, G.L.K., 2003. Genetic divergence in pumpkin. Ind. J. Hort., 60: 363-367.
Lal, T. and Singh S. 1997. Genetic variability and selection indices in muskmelon (Cucumis melo L.). Veg. Sci., 24 (2) 111-117.

Mahalanobis, P. C., 1936. Proceedings of the national academy of sciences on the generalized distance in statistics, 19: 201208.

Pandey, S., Singh, J., Upadhyay, A.K. and Ram, D., 2013. Genetic variability for antioxidants and yield components in Pumpkin (Cucurbita moschata duch. Ex Poir). Veg. Sci., 29: 123-126.

Rahma, M. A., Hossian, M. S., Islam, M. S., Biswas, D. K. and Ahiduzzaman, M., 2002. Genetic variability, heritability and path analysis in snake gourd (Trichosanthes anguina L.). Pakistan J. Bio. Sci., 5 (3) 284-286.

Rao, C.R., 1952, Advanced Statistical Methods in Biometrical Research. John Willey and Sons, New York, p. 357-359.

Sadasivam, S. and Manikeam, A., 1991. Biochemical methods for agricultural science, Wiley Eastern LTD., Newdelhi, p. 25 (1991).

Shipley, B., 2000. Cause and correlation in biology: A User's Guide to Path Analysis, Structural Equations and Causal Inference Cambridge University Press.

Singh, R.K. and Choudary, B. D., 1985. Biometrical method in quantitative genetic analysis, kalyani publisher, New Delhi: 318.

Viswanatha, P. D., 2003. Genetic variability and heterosis studies in musk melon (Cucumis melo L.). M.Sc. (Hort.) Thesis, Univ. Agric. Sci., Dharwad.

Yadav, R. and Ram, H. H., 2002. Correlation and path co-efficient analysis in muskmelon Haryana J. Hort. Sci. 31 (1\&2): 74-76.

\section{How to cite this article:}

Shivappa M. Karadi, V.M. Ganiger, G. Bhuvaneshwari, H.P. Hadimani, M.B. Madalageri and Pallavi, H.M. 2017. Path Analysis and Diversity Studies for Growth, Earliness, Yield and Quality Parameters in Wild Melon (Cucumis melo subsp. agrestis) Genotypes. Int.J.Curr.Microbiol.App.Sci. 6(12): 16121618. doi: https://doi.org/10.20546/ijcmas.2017.612.181 